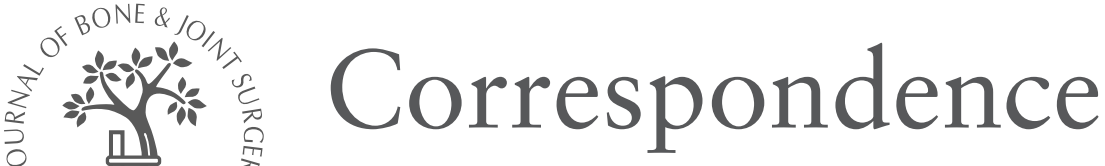

We welcome letters to the Editor concerning articles which have recently been published. Such letters will be subject to the usual stages of selection and editing; where appropriate the authors of the original article will be offered the opportunity to reply.

Letters should normally be under $\mathbf{3 0 0}$ words in length, doublespaced throughout, signed by all authors and fully referenced. The edited version will be returned for approval before publication.

(C)2005 British Editorial Society of Bone and Joint Surgery doi:10.1302/0301-620X.87B1.15864 \$2.00

J Bone Joint Surg [Br] 2005;87-B:135-6.

\section{Complex regional pain syndrome}

Sir,

I read with interest the article by Atkins ${ }^{1}$ in the November 2003 issue entitled 'Complex regional pain syndrome'. In it, he writes: "A bewildering array of treatments have been proposed but scientifically constructed studies are few and uncontrolled investigations are particularly unreliable." He goes on "early treatment gives optimal results", and, less confidently, "Delay in diagnosis and treatment may contribute to a poor outcome." Yet no references are cited in support of these statements.

If the outcome of treatment has not been measured reliably, how can it be said that treatment, however early, influences the outcome of the condition? Generalisations of this nature may assume great medicolegal significance, particularly in cases of alleged clinical negligence.

I should be grateful if Mr Atkins would indicate on what basis these statements were made.

R. G. PRINGLE, FRCS

Burnell House

Shrewsbury, UK.

1. Atkins RN. Complex regional pain syndrome. J Bone Joint Surg [Br]2003;85-B:1100-6

\section{Author's reply}

Sir,

Mr Pringle raises an important issue. Like many areas of clinical medicine the scientific basis of complex regional pain syndrome (CRPS) is incomplete, and my statements are based on the three concepts which direct clinical medicine under these circumstances. These are the scientific evidence which is available, the common experience of clinicians and logical inferences based on these two areas of knowledge.

Every study which has been undertaken suggests that early treatment gives better results. ${ }^{1-3}$ All studies indicate that early mild CRPS is common following trauma, including surgery. The majority of these cases resolve ${ }^{4}$ and the abnormalities of this stage of the condition are potentially reversible. A minority will develop late CRPS with severe contractures. ${ }^{5,6}$ However, minor disability is common after even mild CRPS. ${ }^{7}$ Logically, therefore, many of the patients have mild and often unrecognised CRPS which is treated successfully by physiotherapy and analgesia. Most clinicians would agree that, where swollen, immobile limbs are left untreated, late contractures may occur and which can often, but not universally, be prevented by early physiotherapy. Furthermore, since the late features of CRPS are irreversible once they have occurred, treatment cannot produce a normal limb.

Therefore, early treatment will give optimal results and delay in diagnosis and treatment may contribute to a poor outcome.

\section{R. M. ATKINS, MA, DM, FRCS \\ Bristol Royal Infirmary}

Bristol, UK.

1. Katz MM, Hungerford DS. Reflex sympathetic dystrophy affecting the knee. J Bone Joint Surg [Br] 1987;69-B:797-803.

2. Cooper DE, DeLee JC. Reflex sympathetic dystrophy of the knee. J Am Acad Orthop Surg 1994:2:79-86.

3. Cooper DE, DeLee JC, Ramamurphy S. Reflex sympathetic dystrophy of the knee: treatment using continuous epidural anaesthesia. J Bone Joint Surg [Am] 1989;71-A 365-9

4. Bickerstaff DR. The natural history of post traumatic algodystrophy, MD thesis. Department of Human Metabolism and Clinical Biochemistry, University of Sheffield, 1990

5. Bacorn R, Kurtzke J. Colles' fracture: a study of two thousand cases from the New York State Workmen's Compensation Board. J Bone Joint Surg [Am] 1953;35-A 643-58.

6. Plewes LW. Sudek's atrophy in the hand. J Bone Joint Surg [Br] 1956;38-B:195-203.

7. Field J, Warwick D, Bannister GC. Features of algodystrophy ten years after Colles' fracture. J Hand Surg [Br] 1992:17:318-20.

\section{Evolution of late presenting developmental dysplasia of the hip and associated surgical procedures after 14 years of neonatal ultrasound screening}

Sir,

We read with interest the article by Wirth, Stratmann and Hinrichs ${ }^{1}$ in the May 2004 issue entitled 'Evolution of late presenting developmental dysplasia of the hip and associated surgical procedures after 14 years of neonatal ultrasound screening'.

The authors included 12331 newborns in their study over a 14year period. This is a birth rate of under one thousand per year, which would suggest a small neonatal unit. The second group of 73 unscreened patients is used as a comparison, but no mention is made of where these patients came from. Were they tertiary referrals for hip dysplasia? Are they a comparable group?

The term developmental dysplasia of the hip as opposed to congenital dislocation of the hip was an advance in terminology. ${ }^{2}$ However, it is important to differentiate between dysplasia and dislocation as the latter requires more complex surgery. The incidence of dysplasia in the community is between $1 \%$ and $8 \%{ }^{3}$ and late dislocation varies between 0.5 to 0.8 per 1000 live births. ${ }^{4-7}$ No distinction is made between the two in those presenting late in this paper. 
Did the patients defined as late presentations arise from the general screening group and if so, were their initial ultrasound examinations reported as normal? The late presentations in this paper appear comparable to those reported in one 'at risk' ultrasound screening programme ${ }^{8}$ but worse than those in other general screening programmes. ${ }^{9}$ The treatment rate is $4.9 \%$ in this series, but only $2.4 \%$ had developmental dysplasia of the hip. This requires further explanation.

The problem with general screening is that it may diagnose more dysplasia, which paradoxically may result in further treatment. There is some controversy regarding the treatment of stable dysplasia. Before advocating intervention we need to assess the effectiveness of treatments, especially in the less severe types of dysplasia. $^{10}$

R. W. PATON, FRCS (ORTH)

H. MUMTAZ, MRCS

Blackburn Royal Infirmary

Blackburn, UK.

1. Wirth T, Stratmann L, Hinrichs F. Evolution of late presenting developmental dysplasia of the hip and associated surgical procedures after 14 years of neonatal ultrasound screening. J Bone Joint Surg [Br] 2004;86-B:585-9.

2. Klisic P. Congenital dislocation of the hip: a misleading term: a brief report. J Bone Joint Surg [Br] 1989;71-B:136.

3. Tönnis D. Congenital dysplasia and dislocation of the hip in children and adults. Berlin: Springer-Verlag 1987:59-61.

4. Macnicol MF. Results of a 25-year screening programme for neonatal hip instability. $J$ Bone Joint Surg [Br] 1990;72-B:1057-60.

5. Bernard AA, 0'Hara JN, Bazin S, et al. An improved screening system for the early detection of congenital dislocation of the hip. J Pediatr Orthop 1987;7:277-82.

6. Williamson J. Difficulties of early diagnostic and treatment of congenital dislocation of the hip in Northern Ireland. J Bone Joint Surg [Br] 1972;54-B:13-17.

7. Godward S, Dezateux C. Surgery for congenital dislocation of the hip in the UK as a measure of outcome of screening: MRC working party on congenital dislocation of the hip. Medical Research Council. Lancet 1998;351:1149-52.

8. Paton RW, Hossain S, Eccles K. Eight-year prospective targeted ultrasound screening program for instability and at-risk hip joints in developmental dysplasia of the hip. J Pediatr Orthop 2002;22:338-41.

9. Clegg J, Bache CE, Raut VV. Financial justification for routine ultrasound screening of the neonatal hip. J Bone Joint Surg [Br] 1999;81-B:852-7.

10. Wood MK, Conboy V, Benson MK. Does early treatment by abduction splintage improve the development of dysplastic but stable neonatal hips? J Pediatr Orthop 2000;20:302-5

\section{Author's reply}

Sir,

We thank Mr Paton and Dr Mumtaz for their interest in our paper $^{1}$ and for their comments, which gives us the opportunity to discuss the issues raised in their letter.

The routine ultrasound screening programme we established in 1985 aimed to provide screening for all newborns in the area and was able to include about $85 \%$ to $90 \%$ of children. The second group of 73 unscreened children is made up of patients of the same area from which the group I children came, who were surgically treated for developmental dysplasia of the hip but had failed to participate in an ultrasound screening programme. Tertiary refer- rals were excluded from the study. In that sense the second group is comparable.

Not only does the incidence of dysplasia and dislocation of the hip vary, it also depends upon which diagnostic method has been used at which time. ${ }^{2}$ This appears to be the main reason for the regularly high treatment rates in all series of general ultrasound screening. ${ }^{3}$ In our hospital approximately $2.5 \%$ of newborns, who were classified as having type IIa hips, were treated, resulting in an overall treatment rate of 49 per 1000 . Throughout the continuing discussion about the best way of screening for developmental dysplasia of the hip, this fact has been mistaken for unnecessary overtreatment.

The cases of late presenting developmental dysplasia of the hip were predominantly type III and IV hips, and only five arose from the general screening group; the initial ultrasound was reported to be type IIa in all five cases but the follow-up protocol was violated. The arbitration between necessary and unnecessary overtreatment is often very difficult.

We did not attempt to address precisely the incidence of dysplasia or dislocation of the hip. The aim of the study was to point out clearly that a general ultrasound screening programme leads to a reduction of late presenting cases and surgical procedures associated with developmental dysplasia of the hip. The article does not say that this goal cannot be achieved by an excellent "at risk" or selective ultrasound screening programme. ${ }^{4,5}$ However, there was not a single case of late presenting developmental dysplasia of the hip in five successive years, a result which matches the Coventry experience. 6

It is worrying, however, that three more cases were detected in the region between 1999 and 2002 which were not screened in our department, at a time when general ultrasound screening is required by law in this country.

In order to minimise the numbers of late presenting cases of developmental dysplasia of the hip, it is mandatory to maintain an extremely high diagnostic standard regardless of whether a selective or general ultrasound screening programme is preferred.

\section{T. WIRTH}

Philipps-University

Baldingerstrasse, Germany.

1. Wirth T, Stratmann L, Hinrichs F. Evolution of late presenting developmental dysplasia of the hip and associated surgical procedures after 14 years of neonatal ultrasound screening. J Bone Joint Surg [Br] 2004;86-B:585-9.

2. Bialik V, Bialik GM, Blazer S, et al. Developmental dysplasia of the hip: a new approach to incidence. Pediatrics 1999;103:93-9.

3. Grill F, Müller D. Ergebnisse des hüftultraschallscreenings in Österreich. Orthopäde 1997;26:25-32.

4. Paton RW, Hossain S, Eccles K. Eight-year prospective targeted ultrasound screening program for instability and at-risk hip joints in developmental dysplasia of the hip. J Pediatr Orthop 2002;22:338-41.

5. Holen KJ, Tegnander A, Bredland T, et al. Universal or selective screening of the neonatal hip using ultrasound: a prospective, randomised trial of 15529 newborn infants. J Bone Joint Surg [Br] 2002;84-B:886-90.

6. Clegg J, Bache CE, Raut V. Financial justification for routine ultrasound screening of the neonatal hip. J Bone Joint Surg [Br] 2002;81-B:852-7. 